\title{
Matilde Camnodónico
}

Solo

Comencé a tomar las fotos que acompañan esta nota con la intención de ilustrar un disco: Santullo. Escuchar el disco me llevaba a pensar en una persona que andaba con la atención de quien está solo. Caminaba rápido, pensando. Y eso hice. Salí a caminar de noche, sola. Me di cuenta de que los caminos habituales son distintos si uno camina solo y es de noche.

Fue sencillo encontrar lo que veía ese personaje que cantaba; era un lugar que podía ser cualquiera. No era este lugar, era el lugar que aparece cuando uno camina solo y rápido.

Me sedujo de tal modo caminar en esos términos que seguí haciéndolo. Ahora Solo tiene una existencia independiente. 

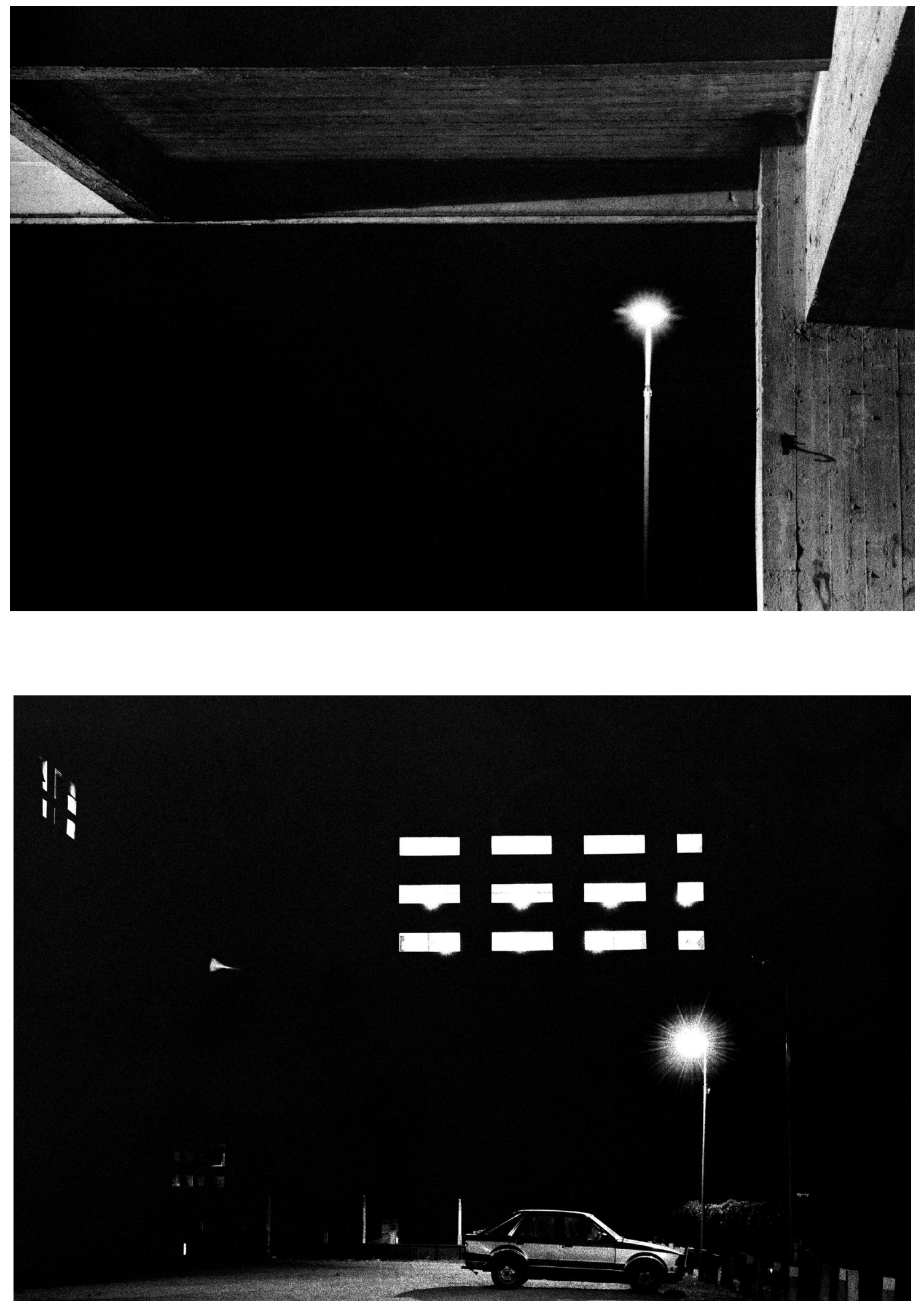


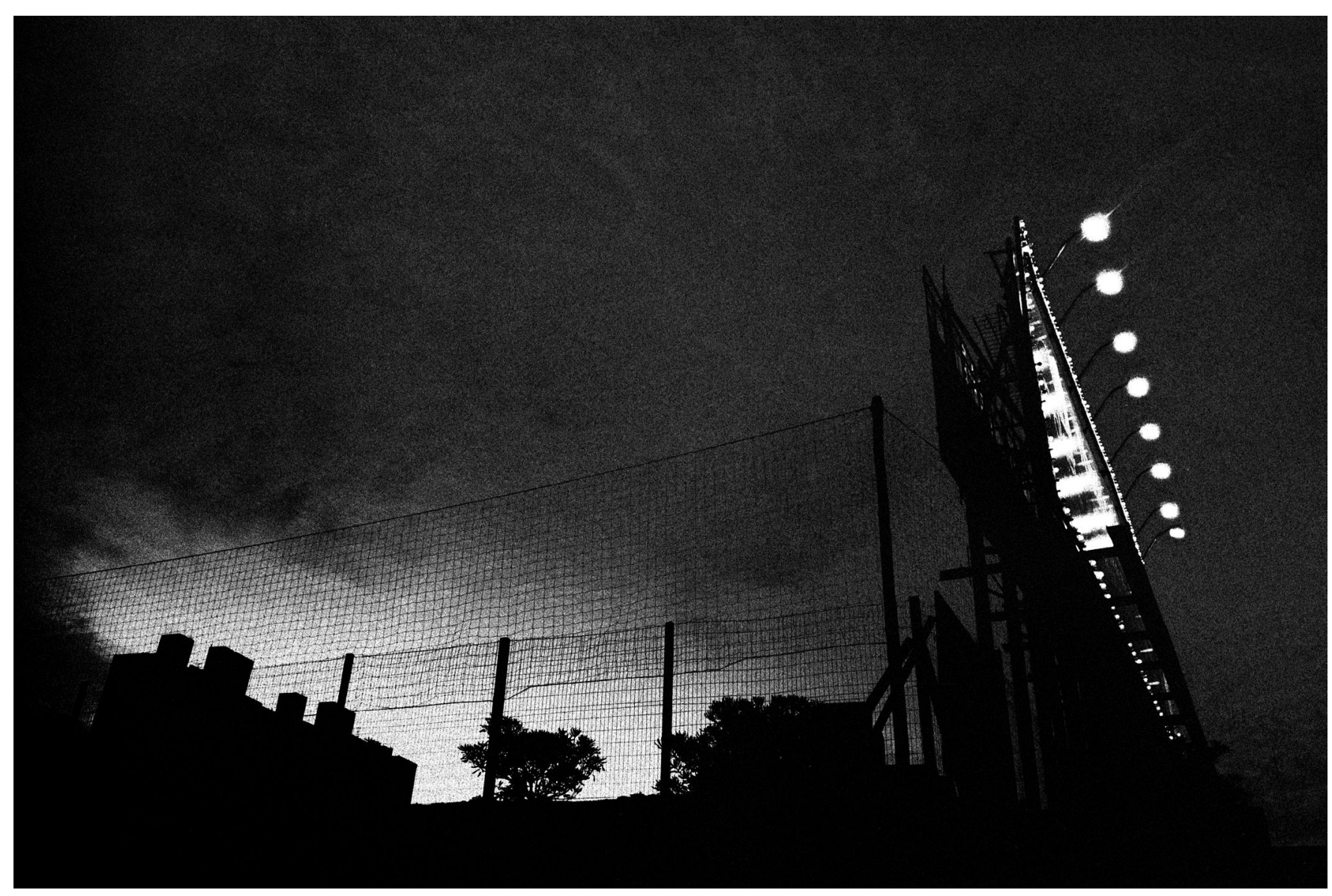




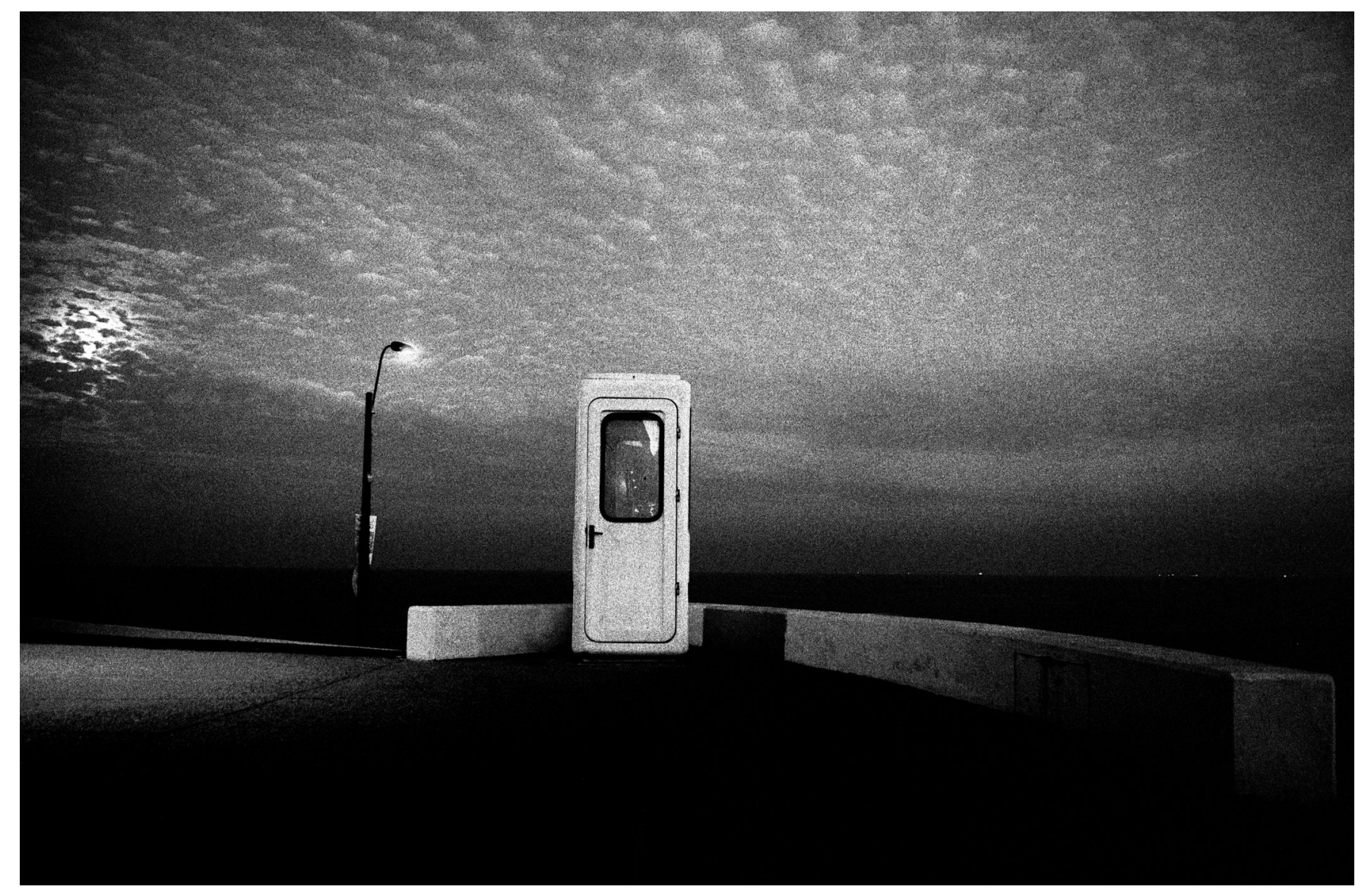



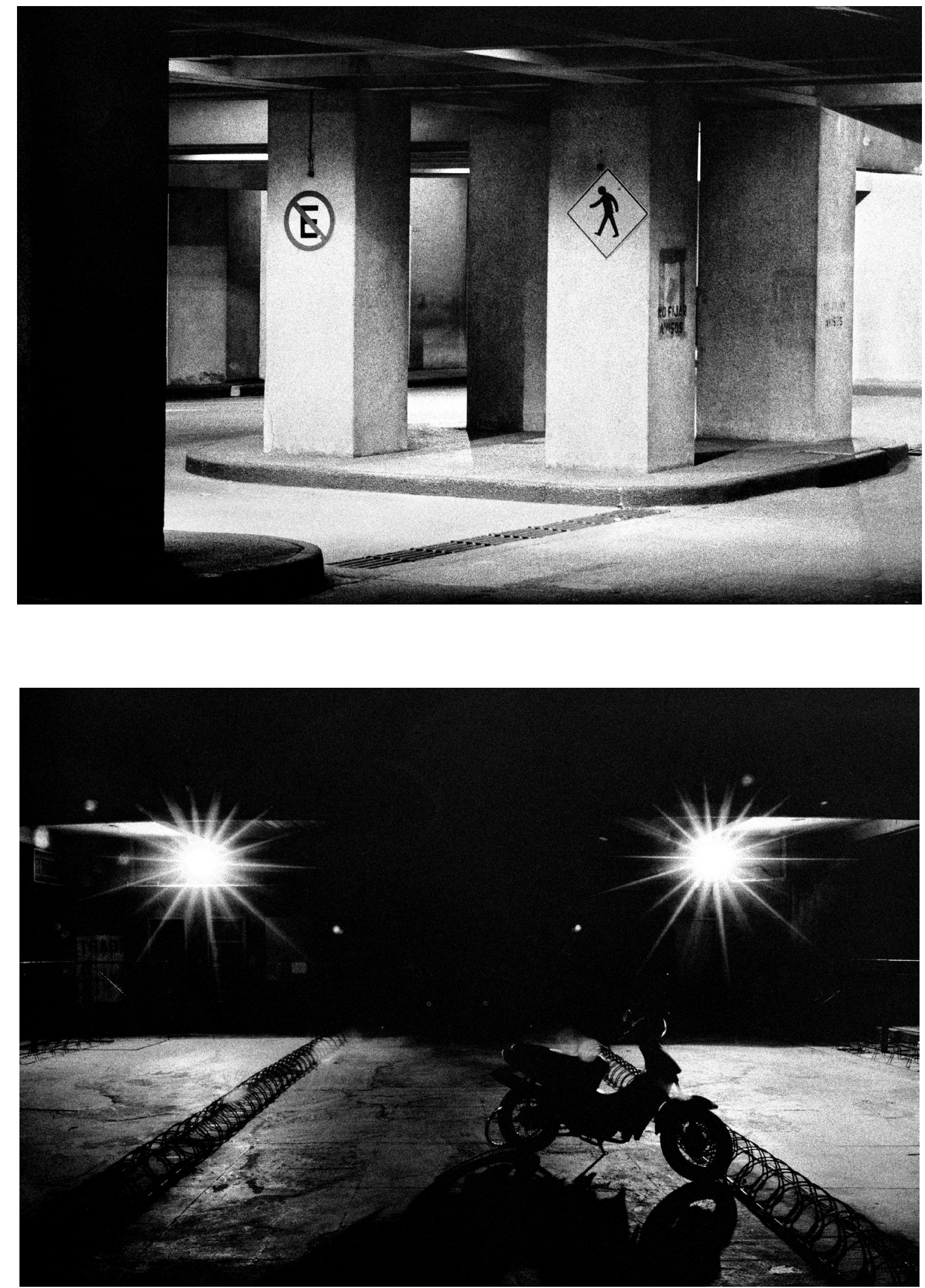
"Intensa. Así defino mi relación con la fotografía. Para mí es difícil pensar en relacionarme con el mundo si no tengo una cámara a mano".

"Una foto siempre inventa un mundo. Incluso las fotos que son notoriamente periodísticas. Cuando uno compone una fotografía intenta que eso que la persona mira sea, durante el tiempo en que se hunde en la imagen, el mundo. Y eso implica creer en una falacia insólita: que algo acotado y en dos dimensiones es el mundo. Eso para mí es fantástico".

"Yo no elegí la música como temática. Más bien estaba ahí, era parte de mi vida. Creci en una familia de teatro y de algún modo mi vida estuvo rodeada de músicos increibles que yo tomaba por personas comunes y corrientes. Mis amigos son músicos, mi esposo es músico, mi hermano es músico. Cuando saco fotos sobre eso, estoy solamente contando cómo es mi vida cotidiana. Trabajar con músicos es trabajar con gente a la que quiero desde que tengo memoria. Lo curioso es que yo no sé nada de música. Cero código, cero estructura. No sé tocar ningún instrumento pero me emociono profundamente. $Y$ eso me hace fácil el trabajo. Comprendo en ese nivel y puedo imaginar cómo se ve eso que estoy oyendo".

"Siempre fui feliz estando en la penumbra mientras el misterio ocurría ahí, debajo de la luz. Es una metáfora interesante de mi vida. Crecí mirando desde el backstage y ese lugar me seduce mucho más que el escenario. Mi infancia pasó entre bambalinas. Cuando era niña recitaba obras de Lope de Vega o de Aristófanes de memoria porque había visto tantas veces los ensayos que aprendía los textos".

Matilde Campodónico 